\title{
Welcome to a New Editor-in-Chief
}

\section{Manfred M. Fischer ${ }^{1} \cdot$ Antonio Paez $^{2} \cdot$ Petra Staufer-Steinnocher $^{1}$}

Published online: 6 November 2019

(c) The Author(s) 2019

The Editorial Team of the Journal of Geographical Systems has remained very stable for a remarkable time. After its foundation by Editors-in-Chief, Profs. Manfred M.M. Fischer and Arthur Getis, Dr. Antonio Páez joined the team as junior Editorin-Chief in 2008 replacing Arthur Getis. Many authors would have been in contact with Dr. Petra Staufer-Steinnocher who for years assisted with editorial matters and who became Associate Editor of the journal in 2018. Regular readers of the Journal will have noticed that, starting in Volume 21, Issue 3 (September 2019), there has been an addition to the Editorial Team, and so it is our pleasure to welcome Prof. Andrés Rodríguez-Pose as a third Editor-in-Chief.

As a past Editor of Economic Geography, and Environment and Planning C: Politics and Space, Andrés brings to the Journal a veritable wealth of editorial experience. We believe that his expertise will strengthen and complement the current expertise of our Editorial Team in GIScience and spatial analysis, spatial econometrics and statistics, and especially in economic geography and regional science.

It is truly a pleasure to welcome Andrés as a new Editor-in-Chief of the Journal of Geographical Systems, and we look forward to working with him in the next years.

Acknowledgements Open access funding provided by Vienna University of Economics and Business (WU).

Open Access This article is distributed under the terms of the Creative Commons Attribution 4.0 International License (http://creativecommons.org/licenses/by/4.0/), which permits unrestricted use, distribution, and reproduction in any medium, provided you give appropriate credit to the original author(s) and the source, provide a link to the Creative Commons license, and indicate if changes were made.

Petra Staufer-Steinnocher

Petra.Staufer-Steinnocher@wu.ac.at

1 Institute for Economic Geography and GIScience, WU Vienna University of Economics and Business, Vienna, Austria

2 School of Geography \& Earth Sciences, McMaster University, Hamilton, ON, Canada 
Publisher's Note Springer Nature remains neutral with regard to jurisdictional claims in published maps and institutional affiliations. 